\title{
Self Governing Seep Out Robocar
}

\author{
Kalaiselvi B, Vijayan T, Sridharraja D, Abinethri R
}

\begin{abstract}
A few pipelines transport different unsafe items, for example, synthetic concoctions, profoundly unstable fluids, and anhydrous alkali, or carbon dioxide. As per information from the 2018 NHIS-OHS, laborers utilized in mining and oil and gas enterprises had high commonness paces of introduction to conceivably unsafe work association attributes and risky synthetic compounds gas spills. In our task we are intending to recognize the careful area of the break. A gas spill locator is a gadget that identifies the nearness of gases in a region, as a major aspect of a word related security framework. This kind of hardware is utilized to identify a gas spill, warmth, fire and different emanations and can interface with a human. A controller can sound an alert to human in the region where the variation from the norm is happening, allowing them the chance to find the break without human hazard. This kind of gadget is significant in light of the fact that there are numerous gases that can be hurtful to human. This undertaking measures and alarms the specialist from this risk. The locator unit will be versatile vehicle based gear. This unit will move alongside the pipe line, screen the air and gives ready messages. The versatile security framework will consistently quantify the warmth, $\mathrm{CO}$ and $\mathrm{H} 2 \mathrm{~S}$ level in the environment or in shut zones where human are working[19],[20],[21]
\end{abstract}

Keywords : co, H2S, controller, temperature

\section{INTRODUCTION}

Numerous pipelines utilized in the transportation of oil based goods and gaseous petrol are recognized by over the ground pipeline markers. A few pipelines transport different unsafe items, for example, synthetic substances, profoundly unstable fluids, and anhydrous smelling salts, or carbon dioxide. Pipeline markers are situated along certain pipeline courses that distinguish the rough area of the pipeline. Everypipeline marker gives basic data to the overall population and crisis responders, for example, the organization that works the pipeline, item moved, and a telephone number that ought to be brought in case of a crisis. Markers might be seen where a pipeline crosses a road, parkway, or railroad. As per information from the 2018 NHIS-OHS, laborers utilized in mining and oil and gas businesses had high commonness paces of presentation to conceivably hurtful work association qualities and perilous synthetic substances gas spills. A considerable lot of these laborers worked extended periods: half worked over 48 hours every week and $25 \%$ worked over

Revised Manuscript Received on August 22, 2019.

* Correspondence Author

B.Kalaiselvi, Department of EIE, Bharath Institute of Higher education and research, Tamilnadu, India. Email: kalaiselvi.eie@ bharathuniv.ac.in

T.Vijayan, Department of EIE,Bharath Institute of Higher education and research, Tamilnadu, India. Email: vijayan.eie@bharathuniv.ac.in

Sridhar Raja D Department of EIE, Bharath Institute of Higher Education and Research, Tamilnadu, India. Email: sridharraja.eie@bharathuniv.ac.in

R.Abinethri, Department of EIE, Bharath Institute of Higher education and research, Tamilnadu, India. Email: abi.eie@bharathuniv.ac.in
60 hours per week in 2010. Furthermore, 42\% worked non-standard movements (not a normal day move). These laborers likewise had high predominance of presentation to physical/compound perils. In 2016, 39\% had regular skin contact with synthetic concoctions. Among nonsmoking laborers, $28 \%$ of those in mining and oil and gas extraction enterprises had visit introduction to used smoke at work. Around $66 \%$ were as often as possible presented to vapors, gas, residue, or exhaust at work. In our task we are wanting to recognize the definite area of the hole. A gas spill locator is a gadget that distinguishes the nearness of gases in a region, as a major aspect of a word related wellbeing framework. This sort of gear is utilized to identify a gas spill, warmth, fire and different outflows and can interface with a human. A controller can sound a caution to human in the zone where the irregularity is happening, allowing them the chance to find the hole without human hazard. This kind of gadget is significant in light of the fact that there are numerous gases that can be unsafe to human. This undertaking measures and alarms the laborer from this threat. The finder unit will be portable vehicle based hardware. This unit will move alongside the pipe line, screen the environment and gives ready messages. The versatile security framework will constantly quantify the warmth, $\mathrm{CO}$ and $\mathrm{H} 2 \mathrm{~S}$ level in the environment or in shut zones where human are working. In the event that the level increments above hello level farthest point, it creates a discernable caution on $0.5 \mathrm{~Hz}$. On the off chance that the level goes above risk, at that point it creates a discernable alert on $0.5 \mathrm{~Hz}$.Petroleum refining is perhaps the biggest business in our nation and a fundamental piece of the national economy. $\mathrm{Be}$ that as it may, potential natural risks related with processing plants have made expanded worry for networks in nearness them. This update gives a general diagram of the procedures in question and a portion of the potential natural perils related with oil treatment facilities. [1],[3],[5]

SEPARATION PROCESSES: these methods encompass isolating the diverse components/hydrocarbon intensifies that make up raw petroleum depending on their breaking point contrasts. Unrefined petroleum for the most element is constituted of the entire scope of segments that make up fuel, diesel, oils and waxes. Partition is often executed by means of making use of environmental and vacuum refining. more getting ready of these divisions is usually expected to create closing items to be bought inside the market place. [2 ], [4],[6] 


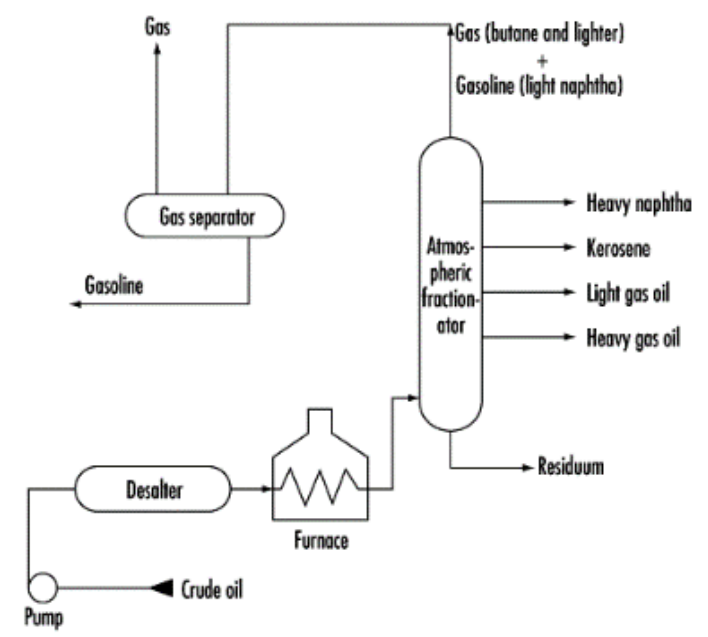

Figure 1: separation process

CONVERSION PROCESSES: Splitting, remodeling, coking, and visbreaking are trade procedures used to split huge longer chain particles into littler ones via warming or making use of impetuses. those approaches enable processing flora to split the heavier oil quantities into different mild elements to build the division of better hobby segments, for example, gas, diesel powers or whatever might be increasingly more helpful on the time. [7],[ 9],[11]

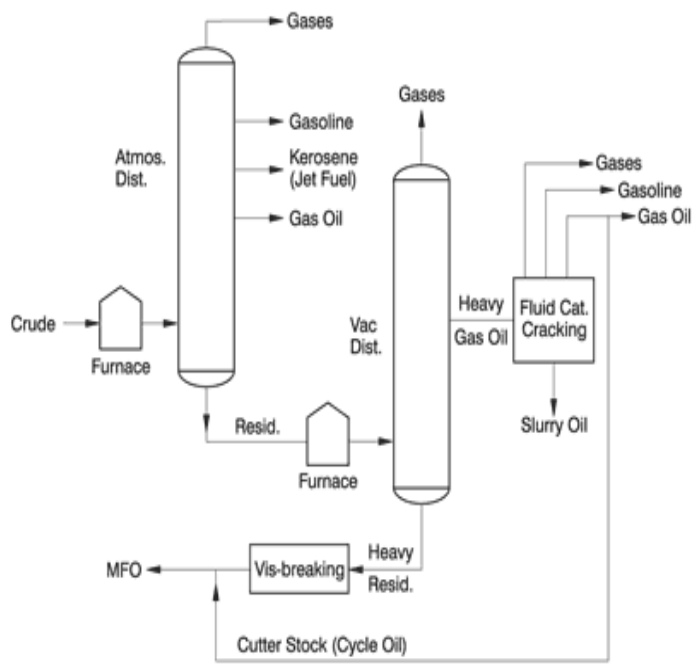

Figure 2: conversion process

Treating: Oil treating approaches are applied to isolate the unwanted segments and contaminations, as an example, sulfur, nitrogen and overwhelming metals from the gadgets. This includes tactics, for instance, hydrotreating, deasphalting, corrosive gas evacuation, desalting, hydrodesulfurization, and enhancing

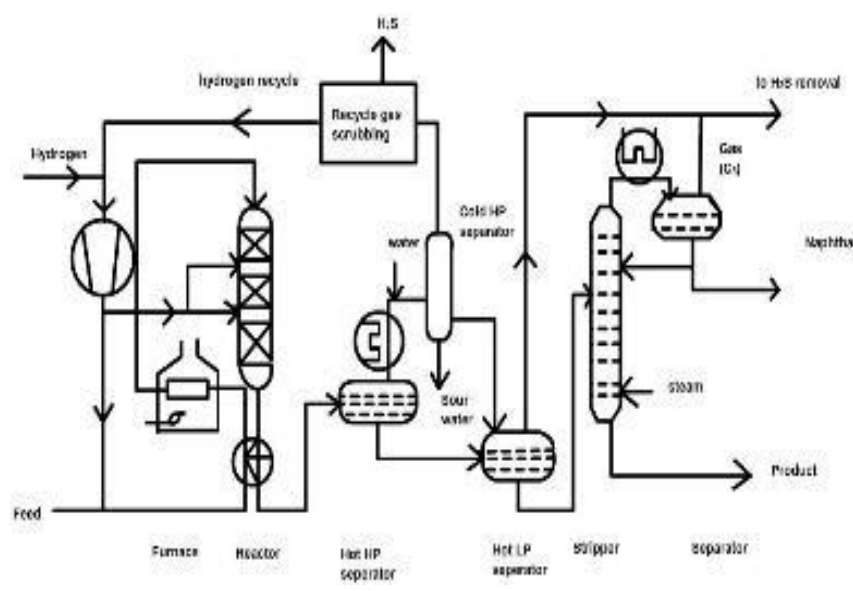

Figure 3: Testing process

COMBINATION PROCESSES: treatment facilities use mixing/mixture methods to make blends with the one-of-a-kind oil components to create a super last object. A case of this progression is be a part of numerous blends of hydrocarbon chains to create greasing up oils, black-pinnacle, or or gasoline with numerous octane appraisals[8],[ 10] ,[12]

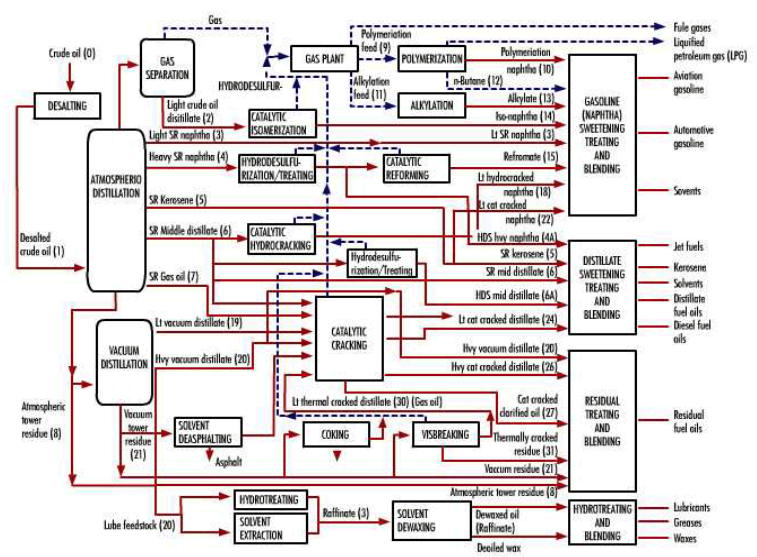

Figure 4: combination process

AUXILIARYPROCESSES: treatment centers moreover have exclusive processes and units which are crucial to activities with the aid of giving pressure, squander treatment and other software administrations. gadgets from those offices are commonly reused and utilized in specific processes in the remedy facility and are likewise extensive with admire to limiting water and air infection. a couple of these devices are boilers, wastewater treatment, and cooling towers[13], [15] ,[ 17]

\section{PIPE LINE GAS LEAK}

The Ports, Oil Refineries and Integrated Petrochemical units are for the most part situated in vicinities and huge amount of oil based commodities are moved through pipelines. Ports assume a significant job in bringing in and supply of raw petroleum to Oil treatment facilities either through pipelines or by tankers wherein, the processing plants engaged with handling of raw petroleum into oil based goods 
which thusly provided to incorporated petrochemical units either through pipelines or by tankers for its appropriation for multipurpose utilization. Enormous amount of raw petroleum and oil based goods are shipped/provided through pipelines laid under or more the ground level. These pipelines become decade old and intended to satisfy the need around then. In addition, these pipelines are laid not considering quite a bit of security and natural perspectives when there was no prerequisite for ecological leeway. However, these pipe lines were laid all things considered of immature zones, yet present situation demonstrates that these pipelines are navigating along street sides through thickly populated territories on substantial traffic stream because of mushroom development of populace and advancement of businesses. As of late, there have been successive bursts and spillages in these pipelines especially at Chennai which prompted sick impact of occupants, defilement of ground water, soil and harm the earth. risky fuel discharges Fires, such as pool fires, fly flames, streak flames and hearth balls. The danger from blasts and weight blasts have to be taken into consideration within the auxiliary structure of manipulate constructing. An method for that is delivered in the ongoing CIA/CISHEC course CIA guidance for the region and structure of concerned structure on compound assembling locales. This considers the helplessness of the shape to ability overpressures related with specific events. systems need to be intended to withstand an overpressure so that it will assure that risks to humans inside the shape are under first-class cutoff factors. particular consideration ought to accept to the association of windows, the nearness of overwhelming hardware on rooftops (for instance compelled air systems) and the ability of inward apparatuses to face up to the shape shaking. at the off danger that windows are available, notion must take delivery of to the utilization of protected or polycarbonate glass, to preclude genuine harm to occupiers of the manipulate room in case of an overpressure. ALARP requirements need to be carried out in these contemplations and cash saving gain used to determine whether greater measures should be carried out. Is brief and precise, and a thermocouple can be made as little because the chief of a stick for tight spaces. no matter the fact that it is able to not be practicable to precisely survey irrefutably the effective ecological temperature, by giving records on dry and wet bulb temperatures and air speed, and using the proper change tables, one can closely examine the encircling temperature the creature is detecting. Air temperature estimations have to be accounted for utilizing the centigrade scale and air pace ought to be accounted for as $\mathrm{cm}$ sec-1 or meters sec-1 for consistency of disclosing. Pipeline spill discovery is utilized to determine whether or not and at times wherein a hole has occurred in frameworks which include fluids and gases. techniques for identity contain hydrostatic testing, infrared, and laser innovation after pipeline erection and hollow vicinity at some stage in management. Pipeline systems are the most monetary and most comfy approach of transportation for oil, gases and different liquid objects. As a methods for long-separation shipping, pipelines want to fulfill tiers of reputation of wellness, unwavering excellent and effectiveness. at the off hazard that appropriately kept up, pipelines can remaining inconclusively with out breaks. most massive releases that do occur are brought approximately by using harm from close by removal. inside the occasion that a pipeline isn't always as it should be stored up, it can erode, specially at improvement joints, depressed spots where dampness gathers, or areas with flaws within the pipe. Be that as it can, these deformities may be distinguished by means of evaluation apparatuses and rectified before they progress to a hole. special functions behind breaks incorporate mishaps, earth improvement, or damage. The basic position of ruin vicinity frameworks (LDS) is to assist pipeline controllers to perceive and restrict spills. LDS give cautions and display other related records to the pipeline controllers to help primary leadership. Pipeline spill reputation frameworks can likewise enhance efficiency and framework unwavering satisfactory gratitude to decreased private time and assessment time. As indicated through the API report "RP 1130", LDS are partitioned into inner based totally LDS and remotely based LDS. interior based frameworks use field instrumentation (for example stream, weight or liquid temperature sensors) to screen internal pipeline parameters. Remotely based totally frameworks make use of an alternate arrangement of discipline instrumentation (as an example infrared radiometers or heat cameras, vapor sensors, acoustic amplifiers or fiber-optic links) to display screen outdoor pipeline parameters. [14],[16], [18]

\section{BLOCK DIAGRAM}

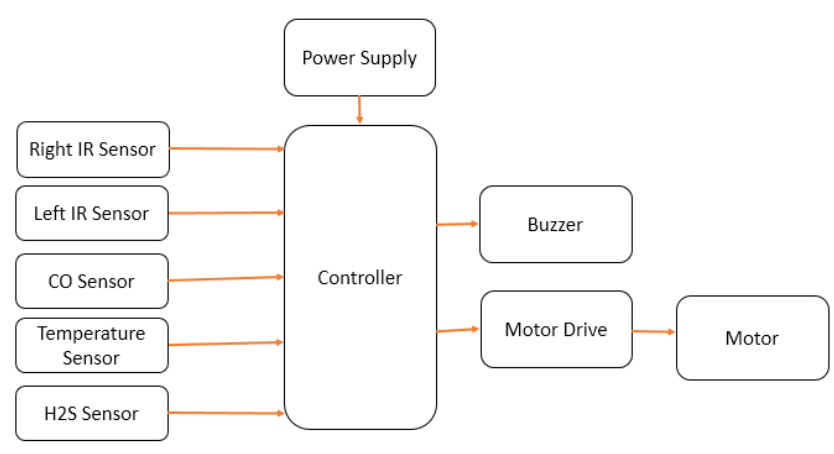

Figure 5: Block Diagram

To realize the proposed model we need to design and test the various hardware and software as listed below:

Hardware Requirement:

- Micro controller

- IR Sensors

- CO Sensor

- H2S Sensor

- Temperature Sensor

- Motor Driver

- Motors

- Buzzer 


\section{CIRCUIT DIAGRAM}

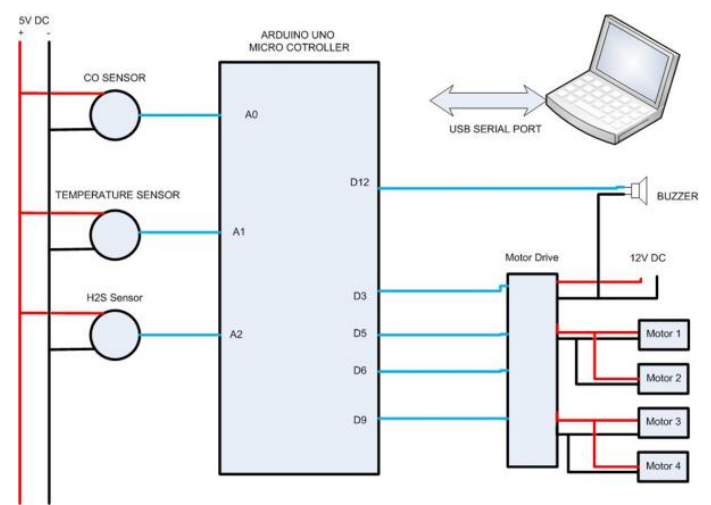

Figure 19: Circuit diagram

\section{FLOW CHART}
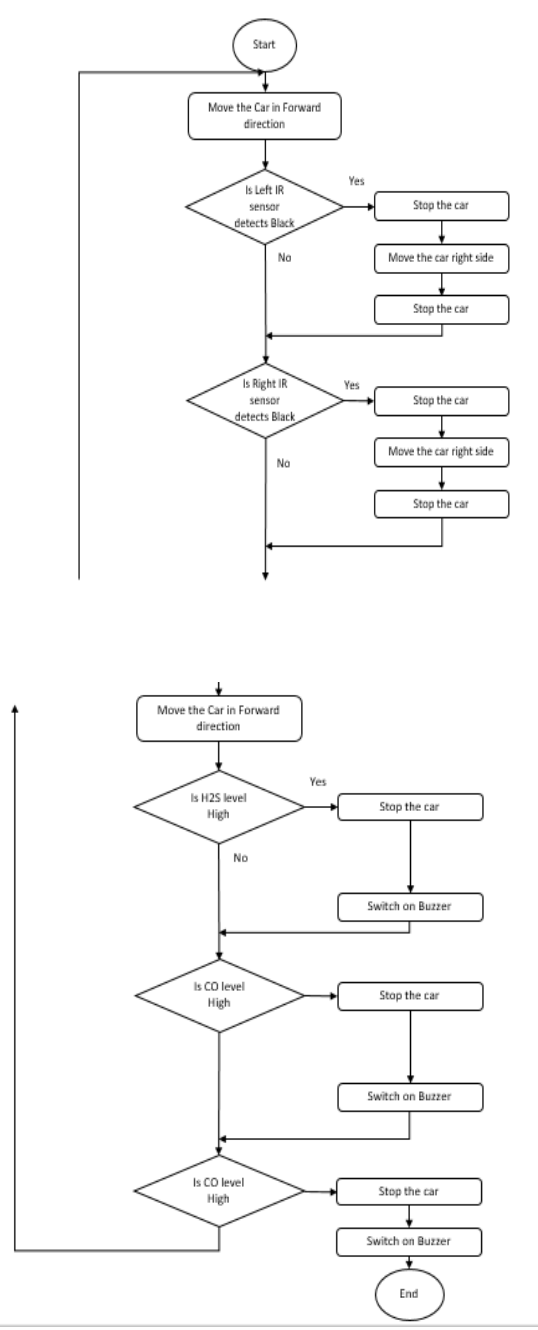

V. RESULTS AND DISSCUSION

- During the movement three parameters( $\mathrm{H} 2 \mathrm{~S}, \mathrm{CO}$, and Temperature) are constantly detected.

- If any of the parameters surpasses as far as possible the vehicle will stop at that area.

- If the $\mathrm{H} 2 \mathrm{~S}$ level is high ( $50 \mathrm{PPM}$ ) at that point signal will sound at $0.1 \mathrm{~Hz}$.

- If the CO level is high ( $60 \mathrm{PPM}$ ) at that point signal will sound at $0.2 \mathrm{~Hz}$.

- If the temperature is high ( $60 \mathrm{Deg} \mathrm{C}$ ) at that point signal will sound at $0.3 \mathrm{~Hz}$.

\section{RESULISAND DISSCUSION}

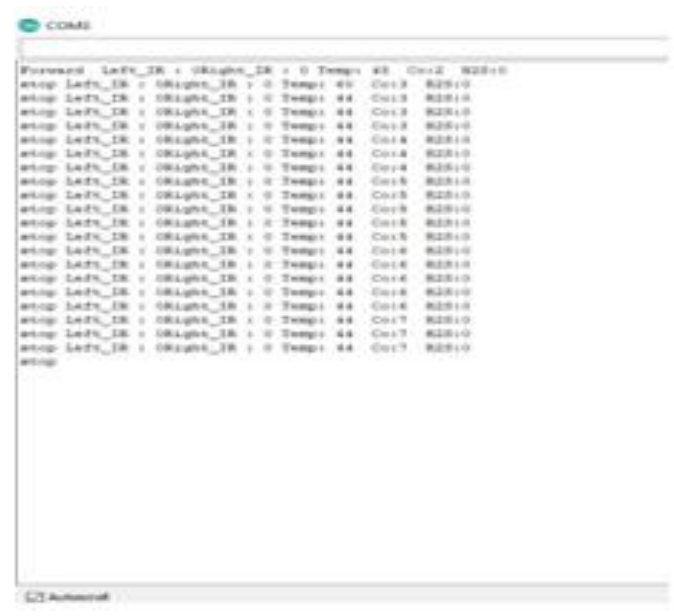

Figure20: initial stage

Published By: 


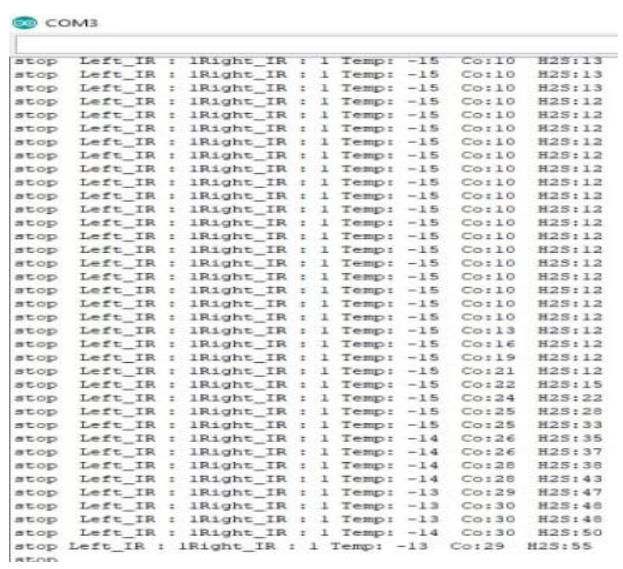

Figure21: Temperture values

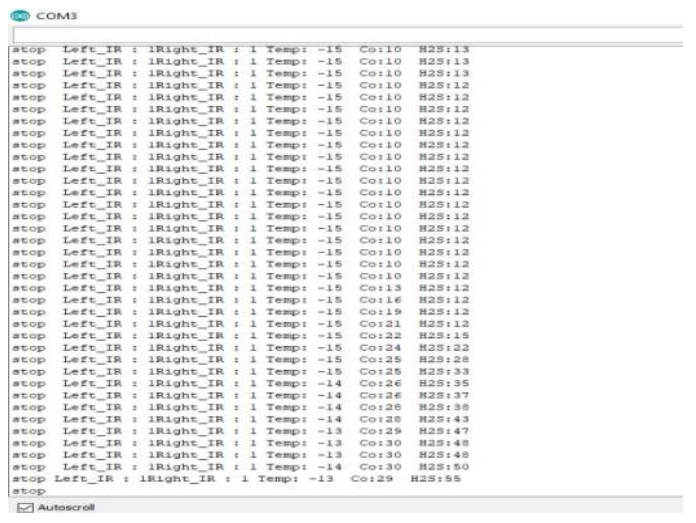

Figure22: H2S values

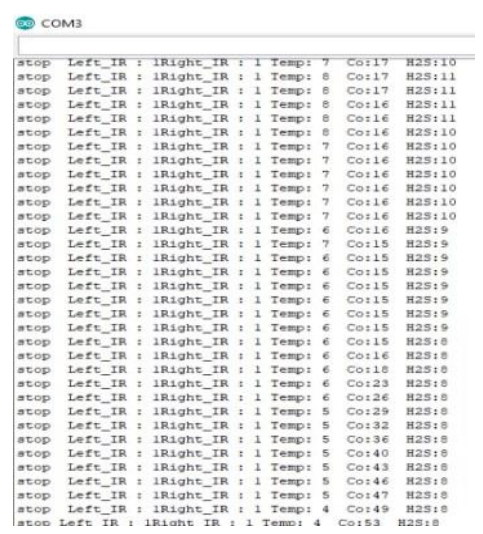

Figure23: $\mathrm{CO}$ values

\section{REFERENCES}

[1] Sharma, R.K., Irusapparajan, G. \& Periyaazhagar, D. 2019, "Three-phase symmetric cascading Z-source seven levels multilevel inverter excited by multi carrier sinusoidal pulse width modulation scheme", International Journal of Innovative Technology and Exploring Engineering, vol. 8, no. 10, pp. 4269-4274.

[2] Velavan, R., Bharanidharan, S. \& Sheeba, B. 2019, "EMF pollution Technology and Exploring Engineering, vol. 8, no. 9 Special Issue 3, pp. 1166-1168 Causes, effects and protection", International Journal of Innovative

[3] Saravana, S., Balaji, S., Arulselvi, S. \& John Paul Praveen, A. 2019, "Reliable power quality monitoring and protection system", International Journal of Innovative Technology and Exploring Engineering, vol. 8, no. 9 Special Issue 3, pp. 644-645.

[4] Tamil Selvan, S. \& Sundararajan, M. 2019, "Performance Parameters of 3 Value $8 \mathrm{t}$ Cntfet Based Sram Cell Design Using H-Spice", International Journal of Recent Technology and Engineering, vol. 8, no. 2 Special issue 5, pp. 22-27.

[5] Jac Fredo, A.R., Abilash, R.S., Femi, R., Mythili, A. \& Kumar, C.S 2019, "Classification of damages in composite images using Zernike moments and support vector machines", Composites Part B: Engineering, vol. 168, pp. 77-86.

[6] Kathiravan, P. \& Govindaraju, C. 2019, "Design and evaluation of ultra gain isolated DC-DC converter for photovoltaic system", International Journal of Engineering and Advanced Technology, vol. 8, no. 5, pp. 2646-2651.

[7] Kripa, N., Vasuki, R. \& Kishore Kanna, R. 2019, "Realtime neural interface controlled au-pair BIMA bot", International Journal of Recent Technology and Engineering, vol. 8, no. 1, pp. 992-994.

[8] Mohanraj, Meenaa Kumari, M., Philomina, S. \& Jasmin, M. 2019 , "In-situ humidity measurement of hydrogen fuel cell car using MEMS sensor", International Journal of Recent Technology and Engineering, vol. 8, no. 1, pp. 41-43.

[9] Velmurugan, T. \& Prakash, S. 2019, "Artificial intelligent based distribution automation of swift fault detection isolation and power restoration for HT network", International Journal of Innovative Technology and Exploring Engineering, vol. 8, no. 6, pp. 1-6.

[10] Dwarakesh, K. \& Prem Kumar, G. 2019, "Five-level inverter based sequential boost system using fuzzy logic controller", International Journal of Innovative Technology and Exploring Engineering, vol. 8, no. 6, pp. 12-19.

[11] Anne Gifta, A. \& Hemavathi, G. 2019, "Analysis of grid tied solar PV system using ANFIS Algorithm", International Journal of Innovative Technology and Exploring Engineering, vol. 8, no. 6, pp. 312-316.

[12] Jayavel, R., Rangaswamy, T.R. \& Prakash, S. 2019, "Efficient grid management system with renewable and conventional power sources", International Journal of Innovative Technology and Exploring Engineering, vol. 8, no. 6, pp. 287-289.

[13] Hemavathi, G. \& Maheshwaran, S. 2019, "Proportional resonant controlled high gain step-up converter system with improved response", International Journal of Innovative Technology and Exploring Engineering, vol. 8, no. 6, pp. 317-323.

[14] Periyaazhagar, D. \& Irusapparajan, G. 2019, "Design and completion of asymmetric single phase 27 level cascaded mli for various pwm scheme", International Journal of Innovative Technology and Exploring Engineering, vol. 8, no. 6, pp. 792-797.

[15] Mahalakshmi, V. \& Vijayaragavan, S.P. 2019, "PV based power electronic converters for high voltage DC applications", International Journal of Recent Technology and Engineering, vol. 7, no. 6, pp. 670-674.

[16] Irusapparajan, G., Periyaazhagar, D., Prabaharan, N. \& Rini Ann Jerin, A. 2019, "Experimental verification of trinary DC source cascaded h-bridge multilevel inverter using unipolar pulse width modulation", Automatika, vol. 60, no. 1, pp. 19-27.

[17] Sangeetha, G., Sherine, S., Arputharaju, K. \& Prakash, S. 2019, "On Line Monitoring of Higher Rated Alternator using Automated Generator Capability Curve Administer", Proceedings of the IEEE International Conference on \&amp;quot;Recent Trends in Electrical, Control and Communication\&amp;quot;, RTECC 2018, pp. 176.

[18] Bycil, V.J. \& Wiselin, M.C.J. 2019, "Modeling and analysis of vibration energy harvesting system using piezo stack", International Journal of Mechanical and Production Engineering Research and Development, vol. 9, no. Special Issue 1, pp. 523-533.

[19] Sripada, A., Warrier, A., Kapoor, A., Gaur, H. \& Hemalatha, B. 2018, "Dynamic lateral balance of humanoid robots on unstable surfaces", International Conference on Electrical, Electronics, Communication Computer Technologies and Optimization Techniques, ICEECCOT 2017, pp. 539

[20] Srinivasan, S., Thirumalaivasan, K. \& Sivakumaran, T.S. 2018 "Performance evaluation of double-output luo converters", Journal of Advanced Research in Dynamical and Control Systems, vol. 10, no. 10 Special Issue, pp. 870-878.

[21] Karthikayen, A. \& Selvakumar Raja, S. 2018, "A skellam distribution inspired trust factor-based selfish node detection technique in MANETs", Journal of Advanced Research in Dynamical and Control Systems, vol. 10, no. 13, pp. 940-949. 


\section{AUTHORS PROFILE}

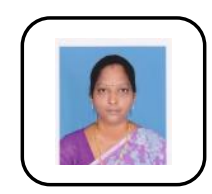

B.Kalaiselvi, Assistant Professor, Department of EIE,Bharath Institute of Higher education and research, Tamilnadu, India

T.Vijayan, Assistant Professor, Department of EIE,Bharath Institute of Higher education and research, Tamilnadu, India.

Sridhar raja D, Assistant Professor, Department of EIE,Bharath Institute of Higher education and research, Tamilnadu, India.

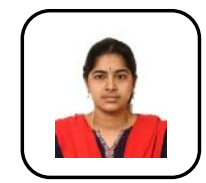

R.Abinethri, Assistant Professor, Department of EIE,Bharath Institute of Higher education and research, Tamilnadu, India 